Aletria, Belo Horizonte, v. 29, n. 1, p. 197-214, 2019

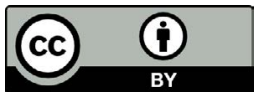

\title{
Anomia no patíbulo: desaparições da legalidade dramática em "O verdugo", de Hilda Hilst
}

\section{Anomie in the Gallows: Disappearances of Dramatic Legality in "O verdugo", by Hilda Hilst}

\author{
Ivan Delmanto \\ Universidade do Estado de Santa Catarina (UDESC), Florianópolis, Santa Catarina / \\ Brasil \\ ivandelmanto@yahoo.com.br
}

Resumo: O ensaio analisa a peça de Hilda Hilst, "O verdugo", e procura revelar, nas modificações realizadas pela autora sobre os modelos originais do drama moderno e do teatro épico europeus, que a obra pode ser melhor compreendida a partir do conceito de "profecia", de Walter Benjamin. O texto de Hilda figura, no contexto histórico do regime militar brasileiro, uma antecipação das estratégias de violência estatal que marcariam um trauma coletivo na formação histórica do país. Tais estratégias do regime fizeram conviver a dominação legal com práticas de tortura e de desaparecimento de opositores, e estão sedimentadas no tecido formal da dramaturgia de "O verdugo".

Palavras-chave: dramaturgia; teatro brasileiro; Hilda Hilst; teoria crítica.

Abstract: We analyze Hilda Hilst's play, "O verdugo", and seek to reveal the modifications made by the author to the original models of European modern drama and epic theater. In this way, the play can be better understood from Walter Benjamin's concept of "prophecy". Hilda's text, within the historical context of the Brazilian military regime, is an anticipation of the violence strategies developed by the State that would mark a collective trauma in the country historical formation. Such regime strategies have brought about legal domination with practices of torture and forced disappearance of opponents and are sedimented in the formal structure of "O verdugo"'s dramaturgy. Keywords: dramaturgy; Brazilian theater; Hilda Hilst; critical theory. 
Pertencente te carrego:

Dorso mutante, morte.

Há milênios te sei

E nunca te conheço.

(Hilda Hilst, Da morte. Odes mínimas.)

\section{Da morte}

É comum a constatação, na fortuna crítica da obra de Hilda Hilst, de que a sua dramaturgia ocupa uma posição periférica em relação à prosa e à poesia. Concentrada nos três últimos anos da década de 1960, seus textos para o teatro foram produzidos durante um período de dedicação exclusiva ao gênero.

À exceção da única peça mais conhecida, "O verdugo", todo o material ficou inédito em livro até 2000, quando foram lançadas quatro das peças pela editora Nankin. A edição do conjunto integral das peças ocorreu novamente apenas na edição da Globo, em 2008. ${ }^{1}$

Em ensaio sobre o panorama teatral do final dos anos sessenta, Anatol Rosenfeld afirma que

embora peças suas [de Hilst] já tenham sido encenadas com êxito por grupos amadores $(O$ Rato, $O$ Visitante, $O$ Novo Sistema), uma delas, na Colômbia, por ocasião de um festival, sua obra ainda não encontrou a acolhida dos grupos profissionais. ${ }^{2}$

Talvez este caráter de quase ineditismo seja responsável por juízos como os de Pécora, para quem há no teatro da autora uma espécie de "Hilda menor":

Ao escrever todas as suas peças nesses poucos mais de dois anos exuberantes, Hilda Hilst dava mostras de entender o apelo único que o teatro representava naquele momento. Pode-se dizer que foi uma produção de ocasião, mas não uma produção oportunista, pois estavam e estão lá os problemas que se tornariam centrais em sua obra em prosa,

${ }^{1}$ PÉCORA. Hilda menor: teatro e crônica, p. 2.

${ }^{2}$ ROSENFELD. Prismas do teatro, p. 168. 
que então mal começava a existir. Ou seja, de certo ponto de vista, o efeito mais importante de seu teatro foi o de ensaiar a sua prosa. ${ }^{3}$

Ainda segundo Pécora, os textos teatrais de Hilst funcionariam como uma etapa de sua formação, ensaio e tentativa de mediação entre sua produção lírica inicial e a prosa vigorosa que se inicia com Fluxofloema. Graças à sua pesquisa com a linguagem teatral, a autora teria superado as fronteiras tradicionais entre os gêneros literários para realizar narrativas em que

seu processo de composição mais nucelar, a saber, o fluxo de consciência, recebe um tratamento marcadamente dramático que tem menos a ver com uma personagem ensimesmada, $[\ldots]$ que com uma geração contínua de personagens que se desdobram em confronto contínuo. ${ }^{4}$

Essa espécie de cisão dramática está presente na narradora de "Unicórnio", novela de Fluxo-floema, em que o foco narrativo se apresenta no conflito de uma voz desdobrada em permanente diálogo consigo:

Não, não, você não é contista...e quer saber mesmo? Olhe, a linguagem é deficiente [...] não fique triste, quem sabe mais tarde você consegue, hein? Quer que eu te segure as mãos? Sim, quero muito que você me segure as mãos. ${ }^{5}$

Para Marcos Santos, em um momento histórico em que a resistência artística à ditadura civil-militar brasileira exercitava suas armas críticas, principalmente no teatro, com o destaque de grupos como o Teatro de Arena, o Oficina e o Opinião, além da ação itinerante dos Centros de Cultura Popular,

é interessantemente nesse período que Hilda Hilst, isolada em sua Casa do Sol, começa a dedicar-se ao gênero dramático. De acordo com declarações da própria escritora, tratava-se de uma tentativa de estabelecer um vínculo comunicativo com o público. ${ }^{6}$

\footnotetext{
${ }^{3}$ PÉCORA. Hilda menor: teatro e crônica, p. 5.

${ }^{4}$ PÉCORA. Hilda menor: teatro e crônica, p. 3.

${ }^{5}$ HILST. Da prosa, p. 140.

${ }^{6}$ SANTOS. Orfeu emparedado. Hilda Hilst e a perversão dos gêneros, p. 45.
} 
Segundo a própria Hilda Hilst, em entrevista de 1969:

Nós vivemos num mundo em que as pessoas querem se comunicar de uma forma urgente e terrível. Comigo aconteceu também isso. Só poesia já não me bastava [...]. Então procurei o teatro. Considero o Teatro uma arte de elite, mas não no sentido esnobe da palavra. O que eu quero dizer é que o homem quando entra numa sala de Teatro deve sentir uma atmosfera diferente daquela que sente no cinema. Uma sala de teatro deve ser quase como um templo. [...] Tentei fazer isso em todas as minhas peças. ${ }^{7}$

Para estabelecer a comunicação com o público, exigida pelo tempo de exceção, era necessário encontrar uma "forma urgente e terrível", capaz de suprir as lacunas da poesia, incapaz de ocupar o debate público como apenas o teatro conseguia fazer. Entretanto, apesar da tentativa, as peças de Hilst permaneceram sem encenação, com exceção de "O verdugo":

A peça $O$ verdugo teve duas versões. A primeira, que remonta ao texto original, foi laureada em 1969 com o Prêmio Anchieta de Teatro, razão pela qual foi editada no ano subsequente. A outra versão é uma adaptação realizada com o diretor da montagem realizada em 1973, Rofran Fernandes, resultando da incorporação de novos elementos ao texto espetacular. ${ }^{8}$

Tornou-se bastante constante, entre a crítica do teatro de Hilst, o juízo de Anatol Rosenfeld, formulado no prefácio ao Fluxo-floema, que constata a habilidade da autora em transitar por gêneros literários distintos:

É raro encontrar no Brasil e no mundo escritores, ainda mais neste tempo de especializações, que experimentam cultivar os três gêneros fundamentais de literatura - a poesia lírica, a dramaturgia e a prosa narrativa - alcançando resultados notáveis nos três campos. ${ }^{9}$

\footnotetext{
${ }^{7}$ HILST. Hilda Hilst: suas peças vão acontecer. p. 24.

${ }^{8}$ RODRIGUES e ROJO. A eminência da morte na dramaturgia de Hilda Hilst, p. 15.

${ }^{9}$ ROSENFELD. Hilda Hilst: poeta, narradora, dramaturga. p. 13.
} 
Para Rosenfeld, a experimentação da autora com os variados gêneros fora gerada por "problemas de ordem objetiva". Como vimos no trecho da prosa citado acima, depois do seu aprendizado dramatúrgico, Hilda teria realizado procedimentos dialógicos em sua narrativa, rompendo com o ponto de vista unitário do narrador, que pôde ser então configurado por contaminação dramática:

Colocando em outros termos as palavras de Rosenfeld, seria melhor dizer que, nesse caso, para a autora, a forma lírica, na qual plasmara sua obra inicial, já não conseguia sedimentar determinados conteúdos que a escritora gostaria de amalgamar em sua obra. No entanto, esse procedimento não só ocasionou uma mudança de gênero, como também uma espécie de contaminação, uma vez que traços de determinada forma passaram a outra. ${ }^{10}$

Mais do que uma urgência de comunicação gerada pela clausura do regime ditatorial, haveria, nas tentativas de Hilst com o gênero teatral, a busca por solucionar problemas de sua lírica, que a poeta percebia como insuficiente para abarcar determinados conteúdos. Assim, a dramaturgia também apresentaria, como a prosa e a poesia de Hilst, essa característica de "mistura de gêneros". Anatol Rosenfeld sublinha o "teor lírico" presente nessas peças teatrais, "de alta qualidade literária", formada por uma "experimentação de versos coloquiais adequados à cena moderna". A modernidade dessa dramaturgia estaria também em sua tendência "ao expressionismo, em virtude de certa abstração que dá aos personagens cunho arquetípico [...], em termos simbólicos ou alegóricos". ${ }^{11}$ Esse pendor alegorizante dos personagens é encontrado também por Marcos Santos e Alcir Pécora, que percebem em toda obra teatral de Hilda um viés didático, que seria também característica de outras peças do período.

trata-se de um teatro alegorizante, de feitio genericamente didático ou doutrinário, cujo assunto básico gira em torno de uma situação de opressão institucional. [...] Acontece que Hilda, sem deixar de constituir suas peças próximo a esses lugares comuns de época, também introduz variantes notáveis no desenvolvimento deles. ${ }^{12}$

\footnotetext{
${ }^{10}$ SANTOS. Orfeu emparedado. Hilda Hilst e a perversão dos gêneros, p. 11.

${ }^{11}$ ROSENFELD. Prismas do teatro, p. 168.

${ }^{12}$ PÉCORA. Hilda menor: teatro e crônica, p. 6.
} 
Pretendo demonstrar neste artigo que a dramaturgia de Hilda Hilst não pode ser completamente compreendida se a considerarmos como uma variante notável dos lugares comuns da época. Se utilizarmos, como lente absoluta para contemplar seus textos teatrais, a característica mais geral de toda sua obra, tanto a lírica quanto a narrativa - a da contaminação entre os gêneros literários -, o resultado será turvo e embaçado. A sua peça mais conhecida, "O verdugo", produz rachaduras importantes na lente crítica do didatismo e da alegorização expressionista e também não pode ser lida sob o prisma da invasão do gênero lírico sobre o dramático: a peça possui uma vertiginosa unidade de ação, em diálogos curtos e em prosa, totalmente ausentes de reflexão intrassubjetiva. A sobreposição e justaposição de gêneros não está presente na peça e a ambiguidade que caracteriza os recursos dramatúrgicos empregados por Hilst habita o que chamarei de uma "anomia dramática", capaz de extrair da situação histórica traumática daqueles tempos uma espécie de "traçado profético", que só pode ser lido se abandonarmos, na leitura crítica da obra, os crivos tradicionais que consideraram o teatro de Hilda Hilst até hoje.

\title{
Presságio
}

Seguirei, a partir de agora, uma pegada deixada por Walter Benjamin, que considerava a história da arte como uma história de profecias:

\begin{abstract}
A história da arte é uma história de profecias. Ela só pode ser escrita a partir do ponto de vista do presente imediato, atual: pois cada tempo possui a sua própria possibilidade de interpretar as profecias que a arte de épocas passadas fizera justamente acerca dele. É a tarefa importante da história da arte decifrar, nas grandes obras do passado, as profecias em vigência na época de sua concepção. ${ }^{13}$
\end{abstract}

Para que, no entanto, essas profecias se tornem apreensíveis, "algumas das circunstâncias adiantadas pela obra de arte, frequentemente em séculos, mas também com frequência apenas em anos, devem ter amadurecido". ${ }^{14}$ Como cada época realiza somente as profecias das quais

\footnotetext{
${ }^{13}$ BENJAMIN. Paralipomena e varia à terceira versão, p. 131.

${ }^{14}$ BENJAMIN. Paralipomena e varia à terceira versão, p.132.
} 
é capaz - "como cada obra faz de seu espaço sombrio do porvir um campo de possibilidades sempre sujeito a transformações", ${ }^{15}$ é necessário partir do princípio de que "cada época sonha a seguinte" e de que as obras de arte exigem do crítico algo assim como uma interpretação dos sonhos traumas coletivos de cada contexto histórico.

O contexto de violência promovida pelo Estado, determinado pelo golpe civil-militar de 1964, está claramente figurado na narrativa de "O verdugo". Em uma indeterminada vila do interior, "em algum lugar triste do mundo", ${ }^{16}$ um rebelde, chamado apenas de Homem, é condenado à morte por dois Juízes (Juiz Jovem e Juiz Velho). Em nenhum momento é revelado o crime cometido pelo Homem, apenas ficamos sabendo que:

FILHO - O pai sabe que o homem dizia coisas certas. O homem é bom.

FILHA - Bom, bom (Com desprezo), há, há, ele pôs fogo em todo o mundo. Fogo, só isso. ${ }^{17}$ Vale lembrar, como primeiro rastro da profecia configurada pela peça, que, a partir de 1970, a Força de Guerrilha do Araguaia era autodenominada sob a sugestiva sigla de FOGUERA. A ideia de que a palavra dos revolucionários tinha o poder de "incendiar" a sociedade foi um lugar comum que direcionou grande parte da atuação das forças repressivas brasileiras. Em texto publicado inicialmente na Military Review, em 1990, o Coronel Álvaro de Souza Pinheiro, que atuou no combate aos membros da FOGUERA e da população local, assim definiu a primeira tarefa do Exército naqueles combates:

Todos os dias, às 21:00 h, hora local de Xambioá, um programa com uma hora de duração, em língua portuguesa, ia ao ar pelas ondas curtas da Rádio de Tirana. Tratavase de uma programação especificamente dirigida ao movimento do Araguaia, e os fatos mais recentes ocorridos na área eram transmitidos sempre dando uma conotação heróica à atuação da guerrilha. Havia uma rede rádio de longo alcance integrando a força de guerrilha, uma estação intermediária e Tirana. Desmantelar esta conexão de rádio

\footnotetext{
${ }^{15}$ DIDI-HUBERMAN. Ante el tiempo, p. 146.

${ }^{16}$ HILST. O verdugo, p. 367.

${ }^{17}$ HILST. O verdugo, p. 368.
} 
foi um dos primeiros desafios superados com sucesso pelos órgãos de informações e segurança. ${ }^{18}$

Mas as palavras do Homem, protagonista emudecido de "O verdugo", não se espalham pelo rádio, e também não chegam a incendiar a população da vila, que permanecerá ao lado da decisão judicial. A história é contada sob o ponto de vista do Verdugo, responsável por cumprir a pena de morte do condenado, e de sua família. A peça é dividida em dois atos, seguindo a tradição do drama burguês. O primeiro ato transcorre inteiramente na casa da família, em que o Verdugo discute com a Mulher e a Filha porque não concorda com a pena dada ao Homem:

FILHA - A morte do homem é daqui dois dias.

FILHO - O pai não vai fazer o serviço.

MULHER - Cala, menino. Cala. Come.

FILHO - Hein, pai?

VERDUGO - (manso) Não sei, meu filho, não sei. ${ }^{19}$

Durante a discussão, em cena que alegoriza a confusão entre espaço público e privado que caracteriza a história do Estado no Brasil, os dois Juízes fazem uma visita ao Verdugo, e oferecem um prêmio em dinheiro para que ele recue e cumpra seu dever. Diante da negativa insistente do Verdugo, os Juízes o aprisionam e o substituem por sua Mulher que, mascarada, comparece ao patíbulo para executar a condenação. No segundo ato, há um deslocamento do espaço da ação, que se transfere para a praça da vila, diante da forca. O Verdugo ainda tenta, depois de escapar, alertar o povo para a fraude, desmascarando a própria mulher e a estratégia dos Juízes, mas é assassinado junto com o Homem. Apesar de ter sido condenado por suas palavras possivelmente incendiárias, o Homem profere uma única fala, durante todo o drama:

HOMEM - (lentamente) Eu não soube dizer. Eu não soube dizer como devia. Eu não me fiz entender. Eu não me fiz entender. (para o Verdugo). Faz o teu serviço. ${ }^{20}$

\footnotetext{
${ }^{18}$ PINHEIRO. Guerrilha na Amazônia: uma experiência no passado, o presente e o futuro, p.2.

${ }^{19}$ HILST. O verdugo, p. 371.

${ }^{20}$ HILST. O verdugo, p. 424.
} 
Condenado a desaparecer, por meio de uma presença paralisada em todo o drama, a narrativa do Homem não me parece retratar, como Pécora afirma em sua leitura da obra, a resistência violenta, empreendida pelos grupos da luta armada que combateram o regime ditatorial pós1964.

Assim, se "O verdugo" acentua a feição cristológica do líder revolucionário, $[\ldots]$ também reforça uma tradição de leitura revolucionária do Cristo, $[\ldots]$ o que tende a justificar ou entender a necessidade da violência na luta pelo direito. ${ }^{21}$

Nem mesmo a enigmática imagem final da peça, em que misteriosos Homens-Coiotes aliam-se ao Filho, parece-me justificar a violência revolucionária:

FILHO - (para os homens-coiotes, objetivo) Vamos. Os homens-coiotes atravessam a pequena praça junto com o filho do Verdugo. Quando estão saindo, um foco de luz violenta incide sobre as mãos dos homens-coiotes. As mãos estão cruzadas na altura dos rins, e deve ser visto claramente que são patas de lobo com grandes garras. ${ }^{22}$

Para Alcir Pécora, ao final da peça,

ensaia-se uma justificativa para as grandes "patas de lobo" desenvolvidas pelos "homens-coiotes", como são chamados os que resistem à execução da pena injusta aplicada pelos juízes. É como se, diante da arbitrariedade tirânica, apenas a violência dessas "patas" agisse em favor da instauração da justiça. ${ }^{23}$

Não há nenhum indício, na ação dos Homens-Coiotes, que indique uma resistência à execução da pena aplicada ao Homem. Também não há nada, no transcorrer da peça, que sequer os relacione às palavras de fogo do Homem: um dos Cidadãos apenas os descreve como homens "esquisitos", que "quando falam, suas bocas se enchem de sal". A rubrica final não os faz agir: ambos, acompanhados pelo Filho, apenas olham o

\footnotetext{
${ }^{21}$ PÉCORA. Hilda menor: teatro e crônica, p. 17.

${ }^{22}$ HILST. O verdugo, p. 429.

${ }^{23}$ PÉCORA. Hilda menor: teatro e crônica, p. 17.
} 
corpo do condenado e desaparecem da praça, com suas patas imóveis. Como o foco narrativo da peça está situado sobre os que detêm o poder, é impossível reconhecer ou avaliar as conjecturais ações revolucionárias promovidas pelo Homem. Apenas sabemos que ele foi condenado a desaparecer, não por promover a violência, mas sim por suas palavras:

JUIZ VELHO - Ele não tem mais o direito de falar.

JUIZ JOVEM - Pela lei, ele já está morto. ${ }^{24}$

Acompanhamos, desta forma, durante toda a narrativa, a trajetória de um personagem que não possui mais o direito dramático de falar e de agir: o Homem que "pela lei, já está morto". Há uma vasta tradição no teatro épico de "peças de julgamento", em que talvez o exemplo mais emblemático seja $O$ círculo de giz caucasiano, de Brecht. Hilda Hilst, no entanto, não situa a ação dramática durante o julgamento, mas a transfere para a execução da condenação, momento em que todos os principais conflitos, acerca do destino do protagonista emudecido, já estão decididos. O conflito principal de "O verdugo", portanto, não advém do debate acerca da Justiça, seja a hegemônica, seja a revolucionária; mas, por meio da recusa do Verdugo, acompanhamos o processo de desaparição a que está submetido o condenado. Quando a peça começa, o Homem já está morto não porque tenha participado de qualquer tentativa revolucionária, como seria a FOGUERA, por exemplo, mas sim porque não está mais autorizado a falar. A estrutura formal do drama o condena não apenas ao silêncio - ao conceder-lhe uma única fala - mas à desaparição: apesar de todos mencionarem a sua existência, o Homem não age durante todo o drama porque a dramaturga decide que não acompanhemos a sua trajetória. Ao concentrar o desenrolar da ação sobre o Verdugo, a peça exclui o Homem do território dramático: não sabemos as razões de sua sentença, os seus conflitos internos, as suas ações e nem as suas palavras. $\mathrm{O}$ drama de Hilst o condena a desaparecer das leis dramáticas - formadas pelo primado da ação e do diálogo intersubjetivo -, desde o início.

A discussão da violência revolucionária não está presente na peça porque o foco narrativo não está depositado sobre os que sofrem as injustiças promovidas por aqueles que detêm o poder. A peça ilumina, pelo contrário, o injustificado emudecimento de um condenado, que ousou apenas falar. O arbítrio da pena é seguido pela completa desaparição do

${ }^{24}$ HILST. O verdugo, p. 424. 
condenado, tudo sob aparente cobertura de legalidade. Reside nisso o caráter profético da peça, Hilst soube transformar em ação dramática, já em 1969, uma característica fundamental do opressor regime ditatorial que só seria plenamente compreendida décadas depois:

\begin{abstract}
Por que uma ditadura precisava de "Atos Institucionais" elaborados a partir de um juridiquês cheio de caminhos tortuosos e intenções legalistas? [...] O principal objetivo dos Atos era o reforço legal do Poder Executivo, e particularmente da Presidência da República, dentro do sistema político. [...] Os Atos serviriam para consolidar um processo de "normatização autoritária" que ainda permitia alguma previsibilidade no exercício de um poder fundamentalmente autocrático. ${ }^{25}$
\end{abstract}

Salvo engano, o caráter de profecia, presente em "O verdugo", está sedimentado em sua estrutura dramática particular. Mencionamos, no início deste ensaio, que há um acordo generalizado, na fortuna crítica da autora, que a produção teatral de Hilda Hilst foi bastante influenciada pelo ambiente artístico e político do final dos anos de 1960, condicionado pelas experiências cênicas com o teatro épico, principalmente o teorizado por Bertolt Brecht. No entanto, a forma dramatúrgica de "O verdugo" desmente este contexto teatral, visto que, as principais regras tradicionais do drama estão todas presentes na peça: a linearidade e unicidade da ação, o diálogo intersubjetivo, a predominância do ambiente privado e familiar dos conflitos. Precisamente por respeitar as leis desta forma dramática, que naquele período parecia condenada à incapacidade de tratar dos conflitos de caráter público e histórico, Hilst conseguiu esboçar e profetizar traços essenciais à compreensão da formação histórica do Brasil durante o período do regime civil-militar: uma ditadura que se moveu no terreno pantanoso, e ambíguo, da legalidade da violência estatal.

Levemos em conta uma das características mais decisivas da ditadura brasileira: sua legalidade aparente, ou, para ser mais preciso, sua capacidade de reduzir a legalidade à dimensão da aparência. Tínhamos eleições com direito a partido de oposição, editoras que publicavam livros de

${ }^{25}$ NAPOLITANO. 1964: História do regime militar brasileiro, p. 79. 
Marx, Lenin, Celso Furtado, músicas de protesto, governo que assinava tratados internacionais contra a tortura mas, no fundo, sabíamos que tudo isto estava submetido à decisão arbitrária de um poder soberano que se colocava fora do ordenamento jurídico.[...] Uma ditadura que se servia da legalidade para transformar seu poder soberano de suspender a lei, de designar terroristas, de assassinar opositores, em um arbítrio absolutamente traumático. ${ }^{26}$

Para Safatle, esse aspecto de anomia da ditadura, que ela própria alimentava, ampliava o arbítrio, em vez de suavizá-lo, como defendem ainda hoje muitos dos revisionistas sobre o período. Em "O verdugo", expor uma condenação, legal, mas injusta, de um Homem ao desaparecimento, respeitando todas as regras formais do drama, mas expondo, por meio de irrupções instantâneas, tentativas de subversão a essas regras tentativas não realizadas plenamente -, significa transformar o mundo histórico externo em estrutura interna da obra. Mais do que criar uma obra dramática em um período em que isso parecia impossível, a profecia histórica de Hilst se configura na instabilidade da forma empregada, ou seja, no apenas aparente desrespeito à legalidade dramática. Veremos, a seguir, essa dialética entre aparência e realidade no plano de uma certa "anomia da forma dramática", presente na peça de Hilda.

\section{Júbilo, memória}

Peter Szondi situa a formação do teatro europeu em um processo histórico de longo curso, que se inicia com as diversas manifestações do trágico (teatro grego, teatro elisabetano, teatro clássico francês, teatro romântico) para se consolidar no trajeto revolucionário, que parte do drama burguês, vive um impasse com as contraditórias propostas do drama moderno, até completar-se na ascensão do novo paradigma do teatro épico, que seria responsável por "solucionar a crise do drama".

No plano da forma, as peças do período áureo do drama burguês baseiam-se no primado absoluto do diálogo intersubjetivo e nas unidades de ação, de espaço e de tempo como estruturas fundamentais da narrativa. A partir de 1848, com a emergência de um período de crise do capitalismo e de revoltas por toda a Europa, as promessas do drama

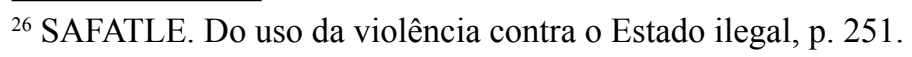


burguês, bem como suas prescrições dramatúrgicas, entram em crise. As novas propostas dramáticas modernas buscam superar essa crise, dando forma a novos conteúdos históricos, por meio de textos que rompem com o primado absoluto das três unidades de progressão narrativa e também com o procedimento do diálogo tradicional, em peças com a presença de monólogos narrativos e líricos e de inatividade dos personagens.

Szondi caracteriza a forma dramática pura a partir de um aspecto fundamental: "Em vez de cantar o heroico, lamenta a dor de um homem simples, no qual os espectadores burgueses podem se reconhecer". ${ }^{27} \mathrm{~A}$ partir dessa centralidade do indivíduo burguês, a mimesis se dá sob o recorte da vida privada do sujeito dramático, o que gera empatia entre o universo sentimental do espectador e o dos protagonistas da cena representada. Segundo pressuposto da ideologia da Ilustração, definido de forma precisa por Kant, a narrativa do drama burguês move-se apenas por meio do diálogo intersubjetivo e da ação unitária e progressiva porque os protagonistas dramáticos devem ser capazes de mover a trama por suas próprias escolhas, determinadas por meio do livre comércio e diálogo democrático entre os sujeitos:

A razão por si só determina o comportamento [...]. A vontade é pensada como uma faculdade de se determinar a si mesma, a agir em conformidade com a representação de certas leis. [...] "Age como se a tua máxima devesse servir ao mesmo tempo de lei universal (de todos os seres racionais) "[...] É a nossa própria vontade, na medida em que agisse tão somente sob a condição de uma legislação universal possível por suas máximas, é esta vontade possível para nós na ideia, que é o objeto propriamente dito do respeito, e a dignidade do homem consiste exatamente nessa capacidade de ser universalmente legislante, ressalvada a condição de estar ao mesmo tempo submetido a exatamente essa legislação. ${ }^{28}$

Posteriormente, a partir da violenta repressão às revoltas europeias de 1848, a ideologia ilustrada torna-se claramente incapaz de responder às agruras do sistema capitalista emergente, que não cumpre mais suas promessas de emancipação e de liberdade. Como expressão desse abismo

${ }^{27}$ SZONDI. Teoria do drama burguês, p. 52.

${ }^{28}$ KANT. Fundamentação da metafísica dos costumes, p. 279-284. 
histórico, a forma dramática também é invadida e negada em seu antigo território de predomínio da subjetividade racional, capaz de decidir, autodeterminada e segundo suas próprias leis universais, seu livre destino. Já em outro importante estudo, Teoria do drama moderno, seguindo os passos de György Lukács, Peter Szondi, a partir da delimitação inicial da teoria estética dos gêneros, aponta o embate entre a forma tradicional do drama burguês e a nova matéria, de viés público e, portanto, épico, que emergiu depois dessa profunda crise do capitalismo, durante a segunda metade do século XIX. Szondi não chega a formular, assim, mas a contaminação épica da forma dramática pura não é apenas resultado de uma espécie de "crise do drama", que teria se manifestado no novo paradigma do drama moderno - um drama em que a crescente contradição entre forma dramática e conteúdos épicos gerou, por fim, um impasse que só pôde ser superado por meio da ascensão da dramaturgia épica. Só é possível compreender o panorama da formação histórica teatral, de longo curso, esboçado por Szondi, se olharmos não apenas para os palcos, mas conseguirmos também identificar as contradições, mais amplas, entre o capital e as lutas dos trabalhadores para resistir ao seu domínio, deflagradas durante aquele momento.

O teatro épico, mirado por Peter Szondi a partir das formulações de Bertolt Brecht, expressa a entrada em cena do operariado, realizando a mudança do diálogo intersubjetivo para o foco narrativo de uma espécie de subjetividade coletiva, capaz de fornecer visada crítica às contradições do capitalismo. Essa modificação da matéria realiza-se por meio de importantes inovações formais, que ampliam o território privatizado do drama para o espaço social. A reificação, consequência do avanço absoluto do capital, não se mostra sob a face de uma segunda natureza, como na dramaturgia do período de predomínio do drama moderno, mas é tratada em sua historicidade, revelada sob o foco narrativo dos espoliados: "faz parte dos fatores históricos de sua gênese [do teatro épico] o fato de que a burguesia, em vez de se impor contra a aristocracia, tem agora de defender a pele contra os trabalhadores". ${ }^{29}$

Assim, para Szondi, a dramaturgia do teatro épico supera as limitações da forma dramática, mantendo aspectos do drama (o diálogo intersubjetivo e a existência da narrativa), mas promovendo sua negação, ao recuperar procedimentos, presentes em outras manifestações teatrais

${ }^{29}$ SZONDI. Teoria do drama burguês, p. 62. 
ocidentais e orientais, que permaneciam barrados da cena dramática: o ponto de vista do coro, a organização da narrativa por meio da montagem de fragmentos, a presença de personagens que são também narradores, a fabulação alegórica.

$\mathrm{Na}$ verdade, tal processo de formação da dramaturgia europeia, com sua periodização entre drama burguês, drama moderno e teatro épico, não se ajusta ao processo de formação de nossa dramaturgia, e esse desajuste contém dados para o conhecimento do processo histórico brasileiro mais geral. No Brasil, mesmo após a realização das primeiras obras dramatúrgicas do teatro épico - o que se deu, entre nós, principalmente pelo CPC, pelo Teatro de Arena e pelo Teatro Oficina o teatro nacional só se forma negativamente, em um percurso de crise constante, não-linear e interrompido, totalmente distinto do europeu.

Esse desajuste está presente em "O verdugo". Afirmei anteriormente que a peça sustenta uma rígida unidade de ação, baseada em conflitos que emergem do tecido privado e familiar. Estaríamos diante de um drama burguês, portanto? Essa primeira classificação genérica não me parece adequada ao objeto: os personagens, que não possuem identidade individual, chamados apenas de Homem, Mulher, Verdugo, Filho, Juiz Velho, parecem aproximar-se da crise do drama moderno, em uma primeira leitura. A ausência de unidade espacial, em que o segundo ato da peça acontece no espaço público da praça, e não mais no lar burguês, inicialmente confirma esse julgamento. Mas a presença, durante o início do segundo ato, de um coro de Cidadãos talvez carregue a peça de Hilst para o território do teatro épico:

CIDADÃOS - (superpondo frases) Mas o que é isso? Ainda é noite. Nem tocaram os sinos. Isso é proibido. Safadeza. É só depois de amanhã. Ainda tinha tempo. Cht! Cht! Mas é noite.

JUIZ VELHO - Tenham calma. Rumores continuam. ${ }^{30}$

O trecho acima é a única inserção coral da peça. Durante o prosseguimento do segundo ato, os Cidadãos continuam em cena, mas agora com vozes singularizadas, divididas entre Cidadão 1, Cidadão 2, Cidadão 3, etc. A presença do gênero épico contesta, mas não chega a contaminar e subverter a legalidade do drama, como no teatro épico

${ }^{30}$ HILST. O verdugo, p. 407. 
europeu. O coro não chega a se configurar, como uma voz coletiva de um grupo social determinado, com uma função crítica sobre a narrativa. É apenas uma interrupção temporária da unidade de ação dramática, um "rumor" como diz a rubrica, que não chega a interferir nas regras do drama, subvertendo-as. O coro de rumores dos Cidadãos possui a função apenas de desestabilizar provisoriamente a estrutura, a máquina do drama, revelando que, sob sua legalidade, esconde-se, sufocada, outra forma narrativa, outro ponto de vista, emudecido, para se contar a mesma história. A breve interrupção épica revela o que a forma dramática, baseada no espaço privado, esconde: a vontade popular. Inicialmente cooptada e confiscada pelos Juízes e depois transformada em garras, patas de lobo dos homens-coiote, a vontade popular não chega a se transformar em ação épica, permanecendo reprimida, incapaz de subverter o território totalitário do drama.

Ao contrário do que afirma Pécora, os homens coiote não estão à espera da revolução iminente, estão esmagados pela própria vigência da legalidade dramática. A história do drama moderno europeu é a história de uma revolta contra a autoridade do drama, contra as leis dramáticas que violentavam os conteúdos de um novo momento histórico e que precisavam ganhar a boca da cena.

No Brasil, assolado pela ambígua violência da ditadura - trauma coletivo escondido sob a legalidade jurídica liberal - o drama de Hilda Hilst sedimenta, em seu esqueleto, essa contradição histórica: em vez de negar as regras dramáticas, o texto expõe, por meio da utilização de procedimentos antidramáticos, a persistência dessa legalidade, abafando as tentativas formais, épicas, de resistência. As tentativas épicas estão presentes na peça, mas, como a resistência democrática dos anos sufocados do golpe, não chegam a se realizar, servindo apenas para disfarçar a hegemonia do Estado autoritário - representado na peça pelo primado totalitário do modelo do drama - apresentado não em estado puro, mas em anomia. A anomia caracteriza-se pelas tentativas épicas de irrupção, que permanecem em estado de rumor, incapazes de instaurar a legalidade de outra forma teatral, assim como a sequência de Atos Institucionais, durante o regime civil-militar, não fundou uma legalidade democrática, mas, pelo contrário, aprofundou o estado de exceção. A peça de Hilst funciona em permanente estado dramático de exceção. 
Aletria, Belo Horizonte, v. 29, n. 1, p. 197-214, 2019

\section{Referências}

BENJAMIN, W. Paralipomena e varia à terceira versão. In: A obra de arte na era de sua reprodutibilidade técnica. Porto Alegre: L\&PM, 2013. p. 145-153.

DIDI-HUBERMAN. G. Ante el tiempo. Buenos Aires: Adriana Hidalgo, 2011.

HILST, H. Da prosa. São Paulo: Companhia das Letras, 2018.

HILST, H. Hilda Hilst: Suas peças vão acontecer, 1969. [Entrevista cedida a] Regina Helena. In: DINIZ, C. (org.). Fico besta quando me entendem. Entrevistas com Hilda Hilst. São Paulo: Globo, 2013. p. 25-27. HILST, H. O verdugo. In: Teatro completo. São Paulo: Globo, 2008.

KANT, I. Fundamentação da metafísica dos costumes. São Paulo: Discurso Editorial; Barcarolla, 2009.

NAPOLITANO, M. 1964: História do regime militar brasileiro. São Paulo: Contexto, 2018.

PÉCORA, A. Hilda menor: teatro e crônica. In: BUSATO, S; REGUERA, M. A. (org.). Em torno de Hilda Hilst. São Paulo: Editora Unesp Digital, 2015. E-book.

PINHEIRO, A. S. Guerrilha na Amazônia: uma experiência no passado, o presente e o futuro. DefesaNet, 2005. Disponível em: http:// www.defesanet.com.br/toa/noticia/5193/TOA---GUERRILHA-NAAMAZONIA--A-Experiencia-dos-Anos-70-Parte-2/. Acesso em: 20 dez. 2018.

RODRIGUES, E.; ROJO, S. A eminência da morte na dramaturgia de Hilda Hilst: $A$ possessa e $O$ verdugo. In: BUSATO, S.; REGUERA, M. A. (org.). Em torno de Hilda Hilst. São Paulo: Editora Unesp Digital, 2015. E-book.

ROSENFELD, A. Hilda Hilst: poeta, narradora, dramaturga. In: HILST, Hilda. Fluxo-floema. São Paulo: Perspectiva, 1970. p. 7-10.

ROSENFELD, A. Prismas do teatro. São Paulo: Perspectiva, 1993.

SAFATLE, V. Do uso da violência contra o Estado ilegal. In: TELLES, E.; SAFATLE, V. O que resta da ditadura. São Paulo: Boitempo, 2010. 
SANTOS. M. L. F. Orfeu emparedado. Hilda Hilst e a perversão dos gêneros. 2010. 145f. Dissertação (Mestrado em Teoria Literária e Literatura Comparada) - Faculdade de Filosofia, Letras e Ciências Humanas da Universidade de São Paulo, São Paulo, 2010.

SZONDI, Peter. Teoria do drama burguês. São Paulo: Cosac \& Naify, 2004.

Recebido em: 31 de dezembro de 2018.

Aprovado em: 19 de março de 2019. 